\title{
How Social Exclusion, Embitterment, and Conspiracy Beliefs Mediate Individual's Intention to Vaccination against COVID-19: Results from a Moderated Serial Mediation Analysis
}

\author{
Dennis Koroma Maria I. Pestalozzi Hansjörg Znoj \\ Department of Health Psychology and Behavioural Medicine, Institute of Psychology, University of Berne, Berne, \\ Switzerland
}

\author{
Keywords \\ Conspiracy theories · Coping · Embitterment · Social \\ exclusion - Vaccination
}

\begin{abstract}
Introduction: As Switzerland faced the "second wave" of COVID-19 incidences, a discussion of a potential vaccine against the virus emerged. While some individuals accept vaccines, others challenge or refuse to be vaccinated, a phenomena called vaccine hesitancy. Here, trust plays a vital role in vaccination intention. Embitterment not only goes along with the sense of being treated unjust but also innates a distrust in others. Thus, embitterment may influence individuals' vaccination intention against COVID-19. In the present study, we investigate how feelings of being socially excluded and the perceived negative impact of the pandemic are associated with embitterment and in turn, how embitterment is related to individuals' vaccination intention and the tendency to hold COVID-19-related conspiracy beliefs (CCBs). This is in regard of the perceived communication style by the government. Method: A convenience sample of 281 individuals completed an online survey developed on Qualtrics. In this cross-sectional, nonexperimental designed study, indirect effects of a moderated serial mediation were
\end{abstract}

karger@karger.com

(c) 2022 S. Karger AG, Basel

www.karger.com/psp

Karger" analyzed using Jamm (Jamovi, Version 0.9; 2019). Results: Results indicated that embitterment went along with increased feelings of social exclusion $(\beta=0.45, p<0.001)$. Further, individuals high in embitterment generally indicated a higher vaccination intention against COVID-19 $(\beta=0.15, p<$ 0.01). However, embittered individuals holding CCBs had a decreased vaccination intention against COVID-19 ( $\beta=$ $-0.71, p<0.001)$. Thus, whether or not embittered individuals develop CCBs might be a crucial determinant for their vaccination intention. Noteworthy, the relationship between embitterment and the tendency to hold CCBs was reinforced by the notion of an unsatisfactory style of communication by the government. Conclusion: Taken together, results suggest that embitterment not only plays a relevant role in vaccination intention against COVID-19 but also for the susceptibility to engage in conspiracy beliefs.

(c) 2022 S. Karger AG, Basel

\section{Introduction}

In Switzerland, as the "second wave» in COVID-19 incidences was observed around November 2020, a significant increase in psychological distress within the population was observed too (see Swiss Corona Stress Study [1]). Coevally, there has been a vivid discussion on a pos- 
sible vaccination on COVID-19. Even though vaccinations have played a considerable role in creating and maintaining public health, the effects and administration of vaccines have ever been defied by individuals or groups; a phenomena that has been termed "vaccine hesitancy" [2]. As several studies have pinpointed, the role of confidence or trust toward government and health care professionals plays a stable factor for individuals being indecisive in their wish to get vaccinated or not [3]. Nonetheless, prior studies investigating the role of confidence lack theoretical-based assessments ([3], p. 18).

\section{Aim of Study}

The present paper proposes a model (see Illustration 1) that investigates this lack in confidence by integrating the construct of embitterment, the role of individuals' sense of social exclusion, and the tendency to hold COVID-19-related conspiracy beliefs on their intention to vaccinate against COVID-19. We argue that trust underlies also aspects of resource conservation in times of resource loss $[4,5]$.

\section{Theoretical Background}

The COVID-19 pandemic has led many individuals to experience a variety of negative effects, such as limitations in social contacts, leisure activities, or restricted mobility. For some individuals, these have not been valuable resources in dealing with the pandemic. As a consequence, some individuals may hold the feeling of being robbed of basic rights by the governments' interventions and process the impact of the pandemic in a bitter way $[6,7]$. Embitterment can be defined as a feeling of disappointment and anger in response to perceived injustices by others toward the self $[8,9]$ and to negative life events $[10,11]$, and is accompanied by feelings of social exclusion [12$14]$, a lack of social support $[10,15]$, and the perception of unrightfully been let down [16]. Notably, as injustices against the individual are considered as a personal threat [13], embitterment reflects a natural response [14], which encompasses a distinct coping response: recompense for impudence. Based on experiences that this cannot be achieved, the individual learns that all efforts chosen are worthless. Following this, the circumplex model of embitterment $[9,13]$ suggests that attributions of embittered individuals build on (a) an external locus of control and (b) hopelessness for change. Conceptually overlapping with the post-traumatic embitterment disorder $([8,14])$, chronic embittered individuals tend to seek amends [11] and distrust their environment, dichotomizing their environment into allies or foes [14, p219]. With regard to the pandemic, some individuals may feel transgressed in their basic value system or lost their job, while others may mourn for the loss of a loved one or had no possibility for valediction [17]. Muschalla et al. [7] recently found an increased trend in embitterment within a large representative-near sample. Results further indicated that embitterment was more related to perception of resource losses due to the pandemic than with virus-related anxieties. Thus, the influence on such pandemic-related negative events might be increasingly perceived as being external and uncontrollable. Therefore, we expect a positive relationship between the perceived negative effects of COVID-19 pandemic and embitterment ( $\mathrm{H} 1$, direct effect $\mathrm{a}_{2}$; for hypothetical direct effects see Fig. 1).

Moreover, these negative effects of the COVID-19 pandemic might also lead to increased feelings of social exclusion, which has been reported by a number of studies [18-21]. Feelings of social exclusion might again enhance a feeling of disappointment and anger and as such increase embitterment. Therefore, we propose both a direct positive connection between the perceived negative impact of the COVID-19 pandemic and the perceived social exclusion ( $\mathrm{H} 2$, path $\left.\mathrm{a}_{1}\right)$ as well as an indirect effect of the perceived negative effects of COVID-19 pandemic on embitterment through the perceived social exclusion (H3, direct effect $\mathrm{d}_{21}$ ).

As the embittered "mindset" tends to attribute toward external sources, feel hopeless in changing the current circumstances, inheres a profound distrust toward their environment, and potentially tend to harm their vicinity ([14], p. 220), it is conceivable that embittered individuals might also distrust vaccines against COVID-19. Therefore, we expect a negative relationship between embitterment and the intent to uptake a potential vaccine against COVID-19 (H4, direct effect $b_{2}$ ).

As previous studies have shown, holding COVID19-related conspiracy beliefs (CCBs) declines the intention of a possible vaccine intake against COVID-19 [22$24]$. Engaging in such beliefs may serve not only as a coping mechanism toward stressful events [25-27] but also serve as a potential source of embitterment [6]. Common CCBs base on the idea that a hidden group or organization stands behind the pandemic [25], being neither visible nor predictable, using the virus only as an expedient for others purposes, such as a (health) dictatorship. Georgiou et al. [25] have found that CCBs were more apparent among individuals holding pre-existing belief system than stemming from present emotional responses. This 
implies that individuals holding particular conspiracy beliefs already had the tendency to attribute events linked to them as being uncontrollable and therefore difficult to influence, which in turn could make embittered individuals more prone to CCBs. Thus, we expect a positive relationship between embitterment and CCBs (H5, direct effect $\mathrm{d}_{32}$ ). Further, as CCBs decline the intention of a vaccine intake against COVID-19, we suggest the negative relationship between embitterment and the intent to vaccinate against COVID-19 to be explained by the tendency to hold CCBs (H6, direct effect $b_{3}$ ). Conclusively, as the perceived impact by the pandemic fosters the intent to vaccinate [28], we expect a positive relationship between individuals' perception of the negative impact of the pandemic and the intent to vaccine (H7, total effect $\mathrm{c})$.

Last, it has been shown that communications play a vital role in public health interventions [29], particularly when addressing behavioral change $[30,31]$. As one may evaluate the communication of the government as unsatisfying, the individual may as a result feel unexpectedly be deprived of potential resources, written off, unrightfully let down by the government, or distrusting the intentions of its public health interventions. Hence, we investigate whether the abovementioned relationships are moderated by individuals' satisfaction of communication by the government in the measures being taken, postulating that the less satisfied the higher are the mentioned effects of embitterment on vaccination intention $(\mathrm{H} 8)$.

\section{Methods}

\section{Design and Participants}

A cross-sectional, nonexperimental design was applied in this study. The survey was created in Qualtrics (Qualtrics Labs Inc.) and took approximately $18 \mathrm{~min}(\mathrm{Md}=18.13)$ to complete. All questionnaires were translated into English, French, and Spanish. Translations were done by native speakers in each language, as well as back-translated by other native speakers. A convenience sample of 281 individuals was recruited from mid-October 2020 until mid-November 2020. It is important to note that this was the time where the "second wave" of COVID-19-detected cases were on the onset in Switzerland (see Swiss FOPH). Participants were sampled from social media channels (e.g., Facebook and LinkedIn). Inclusion criteria for participating were being aged above 16 years. By participating in the survey, individuals had the chance to win in a lottery containing $10 \times$ vouchers of a Swiss online shop worth each 50 Swiss francs. The data were collected anonymously. The email addresses given for the lottery were kept separately so that no connections could be made between the participants and the information given in the questionnaire. In the beginning of the survey, participants were given informed consent. Those accepting the informed consent were advanced to the survey, whereas those not agreeing were led to the end of the survey. Only individuals who had missed out answering $<10 \%$ of overall items of the survey were included in the present study. Ages ranged from 19 to 75 years $(M$ $=41.1, \mathrm{SD}=12.8)$. A total of 195 participants $(70.1 \%)$ were female and 127 held a college degree (45.7\%). Table 1 provides the demographic characteristics of the participants of the study.

\section{Instrumentation}

Main Study Variables

Intention for Vaccination. Intention for vaccination against COVID-19 was assessed by asking the probability (in percent) for getting a vaccination against COVID-19 in March 2021 (if a vaccine was freely available), on a numeric scale ranging from 0 to 100.

\section{Perceived Effects of COVID-19}

The perceived effects of COVID-19 were assessed by asking the participants how much these individuals were negatively affected by the pandemic on 11 areas of life (mobility, physical health, psychological health, spirituality, maintaining social contacts, family life, financial situation, employment/education, intimate relationship/sexuality, leisure activities, and community life) on a range from 0 (not affected at all) - 10 (extremely affected). The areas base on The Valued Living Questionnaire [32], which is used in clinical and nonclinical settings [33]. The scores were arithmetically averaged post hoc and thus resulted in a single factor. Thus, the higher the calculated value, the more negatively affected the individual feels by the pandemic. Internal consistency has proven to be good $(\alpha=0.85)$.

\section{Embitterment}

Embitterment was assessed using the Bern Embitterment Inventory [13]. This measurement captions chronic (trait) embitterment on the basis of 4 aspects, such as Disappointment ("It fills me with bitterness to think of all the goals I have not reached."), Lack of Acknowledgment ("When you make 1 mistake you get criticized immediately however yearlong effort does not get acknowledged."), Pessimism ("I have a pessimistic stance towards life."), and Misanthropy ("I sometimes think that all people are bad and corrupt."). Participants evaluated 18 items on a range from 1 (does not apply) to 5 (applies exactly). Scores were post hoc arithmetically averaged, building a single factor. Here, a higher score indicates a higher degree of bitterness of the individual. Discriminatory ability of the Bern Embitterment Inventory to predict individuals diagnosed with post-traumatic-embitterment disorder is highest beyond a cutoff of 2.15 ([14], p. 217). In this study, internal consistency of the measure turned out to be excellent $(\alpha=0.92)$.

\section{Perceived Social Exclusion due to COVID-19}

Individuals were asked how much the pandemic affect their perceived belonging to society by using the Social Exclusion Scale by Bude and Lantermann [34], addressing individuals' feelings of being disconnected from society (e.g., "I feel that nobody needs me."). On 6 items, individuals stated their agreement on a range from 1 (entirely disagree) to 5 (entirely agree). Scores were then computed to single factor, using the arithmetically average. Hence, a higher score indicates higher stated feelings of being excluded from society, which has previously been shown to be associated with multimorbidity [35] and emotional distress during $\mathrm{CO}$ VID-19 [21]. Internal consistency also turned out to be excellent $(\alpha=0.91)$. 
Table 1. Sample characteristics in number and relative distribution, group differences in embitterment, and vaccination intention

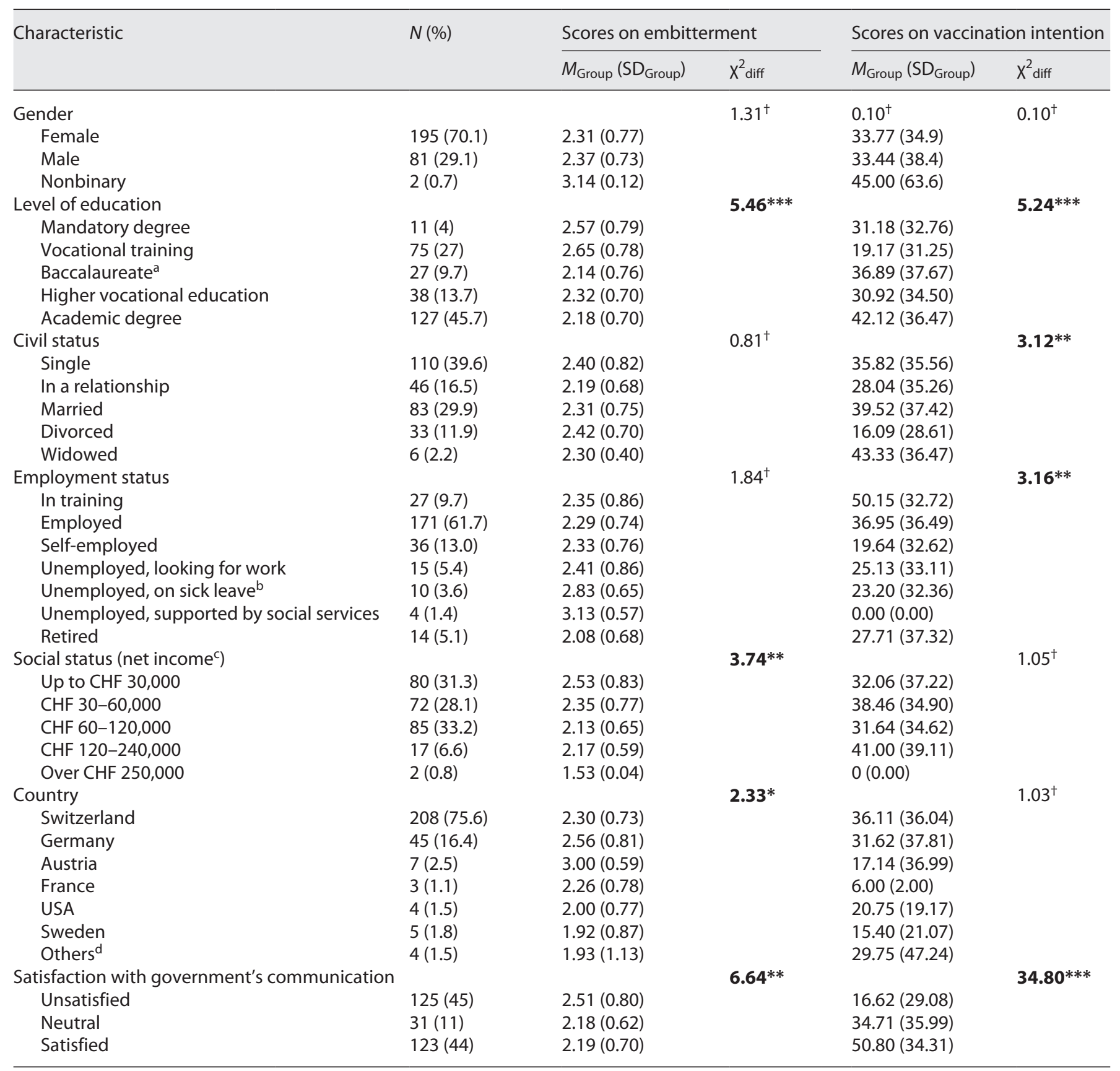

$\mathrm{X}^{2}$ tests were calculated using Fisher's exact test and are marked bold when significant. ${ }^{\dagger} p \geq 0.05,{ }^{*} p<0.05,{ }^{* *} p<0.01,{ }^{* * *} p<0.001$, two-tailed. ${ }^{a}$ Higher school certificate. ${ }^{b}$ Including people with disability pension. ${ }^{c} 1 \mathrm{CHF}$, equals 0.90 EUR. ${ }^{\mathrm{d}}$ Others include Spain $(n=1)$, Portugal $(n=1)$, UK $(n=1)$, and Belgium $(n=1)$.

COVID-19-Related Conspiracy Beliefs

The tendency to hold CCBs was assessed by asking individuals the frequency of having thoughts that, e.g., "Foreign groups are behind the vaccination," "The government is just trying to control us," "A new world order is being created," or "There is a connection to
Bill Gates." Partly based on the study of Georgiou et al. [25], 12 statements were used for evaluation ranging from 1 (never) to 5 (constantly). These 12 statements were then also post hoc arithmetically averaged toward a single factor. Thus, a higher score of this single reflects higher presence of CCBs of an individual. In 


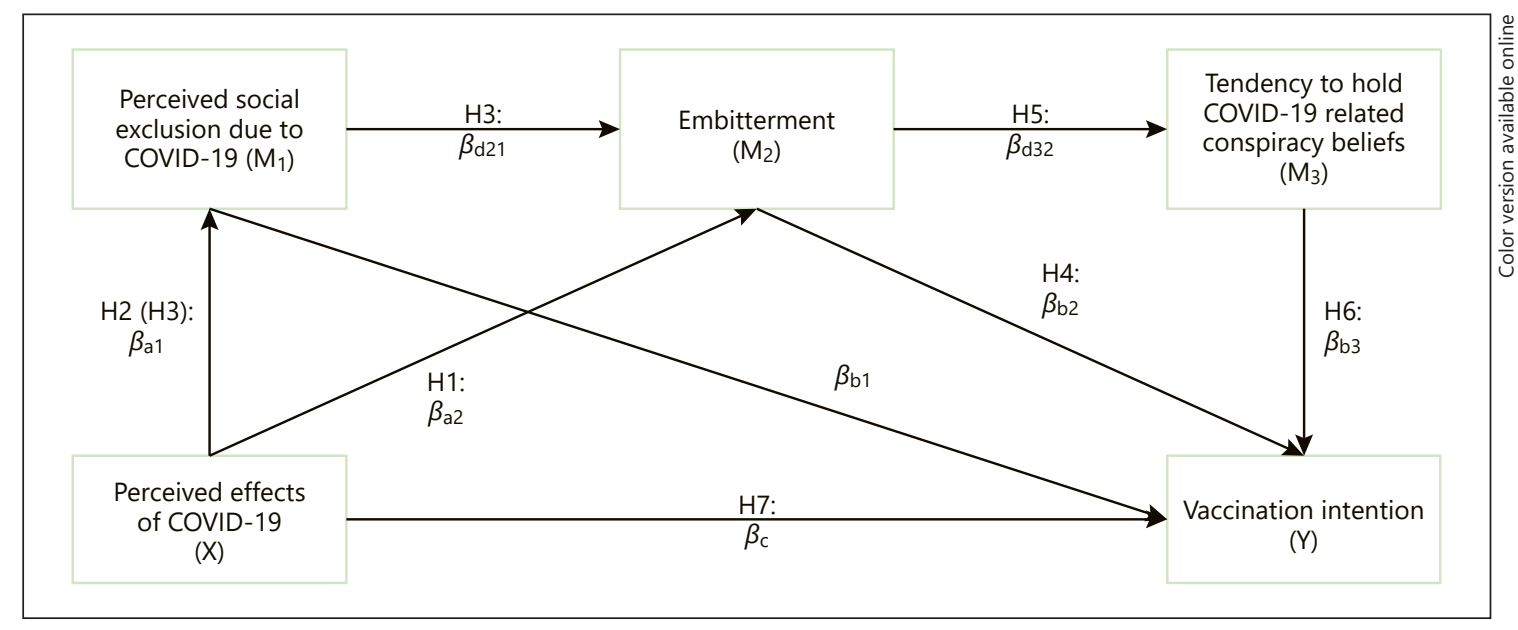

Fig. 1. Structural representation of the hypothesized serial mediation model with 3 mediators $\left(M_{1-3}\right)$, the hypothetical paths $(\mathrm{H} 1-\mathrm{H} 7)$, and corresponding indirect pathways $\left(\mathrm{a}_{\mathrm{x}}-\mathrm{d}_{\mathrm{xx}}\right)$. The model has a proposed antecedent, $X$ (perceived effects of COVID-19); 3 sequential mediators, M1 (perceived social exclusion due to COVID-19), M2 (embitterment), and M3 (tendency to hold COVID-19-related conspiracy beliefs); and 1 outcome variable, $Y$ (vaccination intention). The arrows indicate the linear regression effect from one variable to the other.

terms of internal consistency, items showed excellent intercorrelations $(\alpha=0.97)$.

Satisfaction with Governments Response: Communication

Individuals' satisfaction with the government in responding toward the growing number in incidence was assessed. Here, we particularly asked how the subject evaluated the communication of the measures being taken. Individuals could select an answer ranging from -3 (totally unsatisfied) to 3 (totally satisfied). Again, scores were post hoc computed into 3 categories: unsatisfied (containing $-3,-2$, and -1$)$, neutral ( 0$)$, and satisfied $(1,2$, and 3$)$.

\section{Covariates}

Demographic Background

In virtue of possible group differences having consequences on the intent to vaccination, participants were asked about their age, gender, level of education, employment status, civil status, socioeconomic status (as measured in approx. net annual income), and country of residence. Table 1 shows how these demographic variables play out on embitterment and on vaccination intention.

\section{Agreeableness}

Ever since individuals who are low in the personality trait agreeableness engage more often in conspiracy beliefs [36] agreeableness was assessed using a single unipolar item. This item was ranging from 1 (blunt, cold, critical, easily angered, and suspicious) to 7 (sociable, cooperative, warm, kind, and indulgent).

\section{Procedure}

Answers from Qualtrics were exported to SPSS Statistics (Version 27.0), where items were processed. For deploying a path-model, means of the variables were computed post hoc. Statistical significance was at $5 \%$ level. The Shapiro-Wilk test indicated that the acquired data (beside Perceived Effects of COVID-19) do signifi- cantly $(p<0.001)$ deviate from a standard distribution. To account for the violation in the normality assumption [37] and in order to receiving descriptive statistics, analysis of variances based on Fisher's LSD were processed using jamovi (Version 0.9; 2019). Here, bivariate correlations of the main study variables were computed likewise. For model building, the jAMM-Macro (jamovi; Version $0.9 ; 2019)$ was applied.

In this study, direct and indirect effects were calculated using a serial mediation model. Serial mediation models are mostly used to model complex consequential effects [38]. This statistical approach is being used evermore in psychological research [38-40]. As such, serial mediation models typically inhere a proposed antecedent variable, at least 2 mediating variables with a proposed consequential effect, and an outcome variable [38]. In our model, we entered perceived social exclusion (mediator $(M)_{1}$ ), embitterment $\left(M_{2}\right)$, and CCBs $\left(M_{3}\right)$ as mediators, whereas the perceived effects of COVID-19 was entered as hypothesized predictor (scaling: centered) on vaccination intention (dependent variable). Last, testing the influence of the satisfaction of the governments' response, we entered this variable as a moderator (factor coding: simple), resulting in a moderated serial mediation model (method: enter). Moreover, since all variables of interest but one (perceived effects of CO$V I D-19)$ failed on normality, we examined the proposed direct and indirect effects by estimating bias-corrected standardized regression coefficients (betas) using bootstrap analysis (1,000 bootstrap samples), as bootstrapping is a nonparametrical statistical procedure holding high statistical power which is free of distributional properties [41, 42].

In order to address potential variables that would confound the model, multivariate regression analyses for vaccination intention were carried out, using a stepwise regression. Here the variables from Figure 1 were entered in block 1, age and agreeableness being in block 2 , then education (reference $=$ mandatory school), employment status (reference $=$ student), civil status (reference $=$ single), 


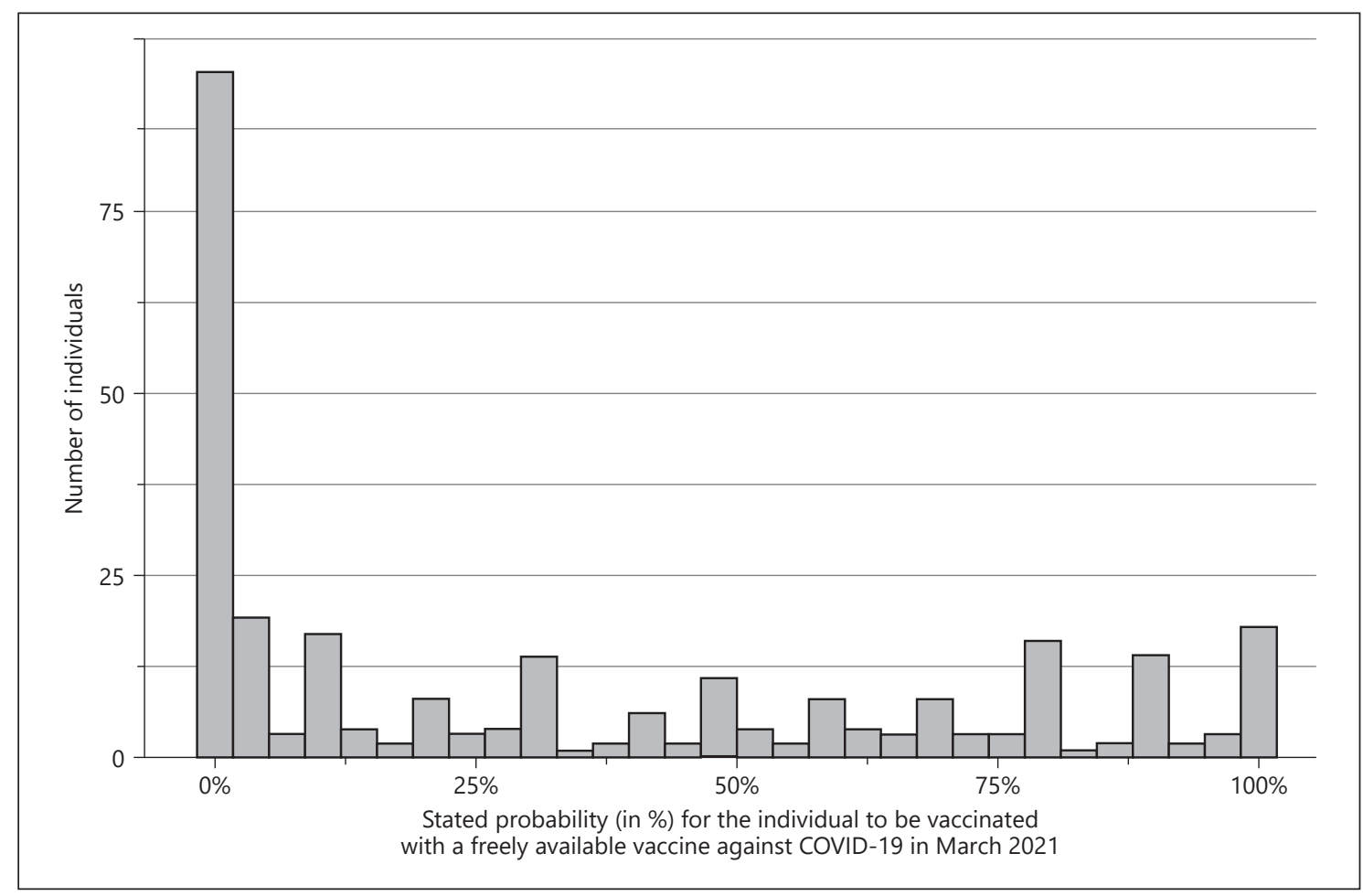

Fig. 2. Frequency distribution of the dependent variable vaccination intention. On the $x$-axis are the stated probabilities (in \%) for each individual to be vaccinated with a freely available vaccine against COVID-19 in March 2021. On the $y$-axis is the number of individuals stating the probability.

socioeconomic status as measured in net annual income (reference $=\mathrm{CHF} 30,000)$, were entered (block 3). Last, with attention to possible influences in terms of divergent public health strategies, country of residence (reference $=$ Switzerland) was entered (block 4$)$.

\section{Results}

\section{Descriptive Statistics}

As shown in Figure 2, overall vaccination intention measured as estimated probability to get vaccinated within the measured sample turned out to be low. In terms of embitterment, moderate values were observed in the sample. Detailed overview of differences regarding the demographic background can be found in Table 1 . The bivariate relationships between the major study variables are listed in Table 2 .

\section{Moderated Serial Mediation Analysis}

The direct effects and statistical values of the moderated serial mediation model are shown in Figure 3. H1: Results show that embitterment was not directly related with the perceived negative impact of the pandemic; hence, no support for hypothesis 1 is shown.
$\mathrm{H} 2$ : Individuals who feel more negatively affected by the pandemic also rated themselves as more socially excluded, supporting hypothesis 2 . This is in line with the results of He et al. [18], Nivette et al. [19], Seifert et al. [20], and Shanahan et al. [21]. H3: Embittered individuals stated to have more feelings of social exclusion, thus supporting hypothesis 3 and being in line with Alexander [12], Znoj [13], and Znoj et al. [14].

$\mathrm{H} 4$ : Contrary to our conjecture, results show that embitterment significantly went along with a higher vaccination intention, which lead to dismissing of hypothesis 4 . H5: Embittered individuals showed a higher tendency to hold COVID-19-related conspiracy beliefs, which is in line with hypothesis 5.

H6: Even though embitterment significantly went along with a higher vaccination intention (see results $\mathrm{H} 4$ ), individuals with the tendency to hold COVID-19-related conspiracy beliefs were strongly less likely to show vaccination intentions. This is in line with results from Earnshaw et al. [22], Freeman et al. [23], and Romer and Jamieson [24]. 


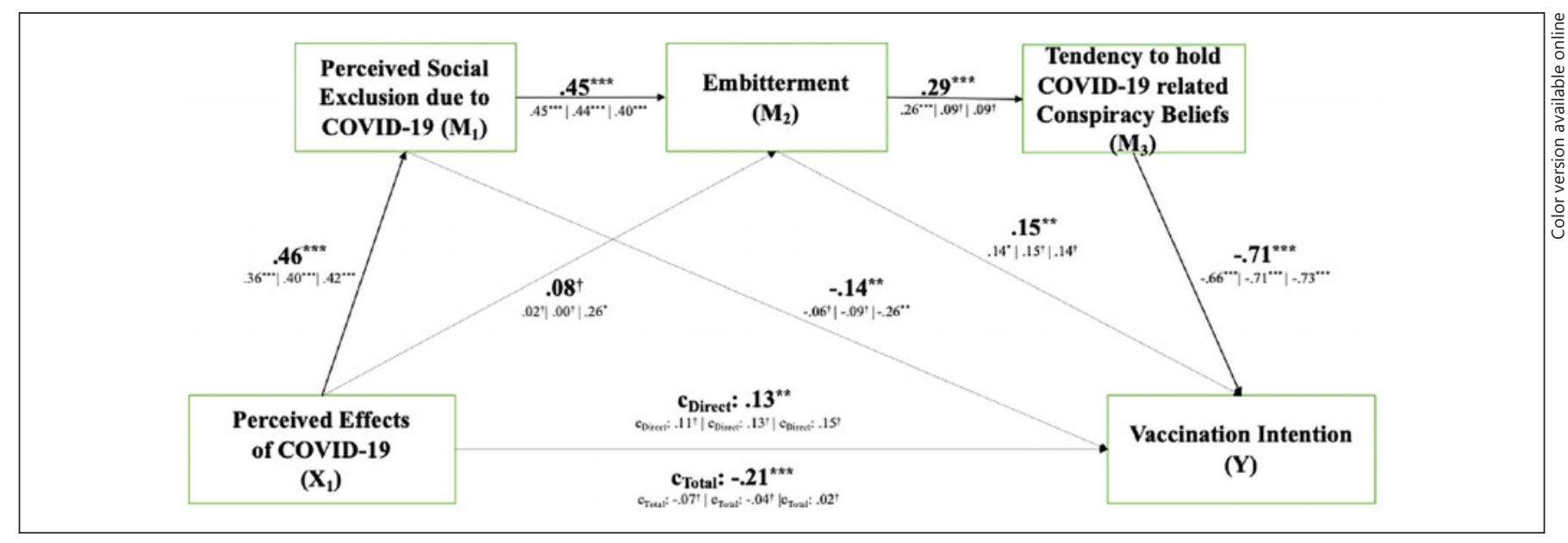

Fig. 3. Results of the moderated serial mediation model. Standardized effect sizes (betas) are marked in bold. Below, moderator levels of satisfaction in government's communication of the measures are: unsatisfied/average/ satisfied. ${ }^{\dagger} p>0.05,{ }^{*} p \leq 0.05,{ }^{* *} p<0.01,{ }^{* * *} p<0.001$. Bootstrap: 1,000 samples.

H7: Individuals who perceived themselves as more negatively affected by the COVID-19 pandemic showed less vaccination intention against COVID-19. Yet, this relationship is significantly inverted when controlling for the perceived social exclusion, embitterment, and the tendency to hold COVID-19-related conspiracy beliefs. Thus, support for hypothesis 7 is found.

H8: To test whether the relationships of the major study variables in the model were influenced by the stated satisfaction in the communication of the measures, this variable was entered as a moderator. With regard to specific indirect effects, results further showed that unsatisfied individuals with higher feelings of being socially excluded, embitterment, and tendency to hold COVID19-related conspiracy beliefs were less likely to show vaccination intentions against COVID-19 (consult online suppl. Table 3 for indirect effects; for all online suppl. material, see www.karger.com/doi/10.1159/000521016). Additionally, for individuals being satisfied with the communication by the government, results showed no relationship between embitterment and the tendency to hold COVID-19-related conspiracy beliefs. An in-depth simple moderation analysis was performed, testing the moderator's effect (satisfaction of communication) on the association between embitterment and the tendency to hold COVID-19-related conspiracy beliefs (consult online suppl. Moderation effects Output). Results pinpoint that embitterment increased the tendency to hold COVID19-related conspiracy beliefs, while the satisfaction with communication decreased individual's tendency to hold
COVID-19-related conspiracy beliefs (main effects). Furthermore, a trend emerged for an interaction effect between embitterment and satisfaction with communication on the tendency to hold COVID-19-related conspiracy beliefs. Accordingly, embitterment was moderately related with the tendency to hold COVID-19-related conspiracy beliefs when individuals were averagely satisfied with the communication of the government. Moreover, this relationship was amplified when individuals showed a decreased satisfaction with the communication. Yet, when satisfied with the communication of the government, embitterment showed no relationship with COVID-19-related conspiracy beliefs (see online suppl. Fig. 4 for simple slopes plot).

Omnibus ANOVA test showed that the variables of the moderated serial mediation model (with exception of the satisfaction with the communication) contributed a significant proportion of the variance explanation of the vaccination intention. The effects of the main variables on vaccination intention remained stable even under the control of age, agreeableness, and demographic background.

\section{Discussion}

This article aimed to propose a theoretically based model that explains which factors are associated with an individual's intent to take a vaccine against COVID-19. We proposed that individuals' intention to take a vaccine 
if available is influenced by feelings of social exclusion, embitterment, and by the tendency to hold COVID19-related conspiracy beliefs. In that, it is the first study that puts individuals' embitterment reasoning style into the equation. Results of the cross-sectionally designed online survey suggest that these factors do indeed interact with individuals' intent to vaccinate. However, the association between embitterment and conspiracy beliefs as well as vaccination intention is moderated by the satisfaction of the communication of the government concerning the COVID-19 pandemic. In the following, possible explanations of these effects are explained with regard to resource losses and gains.

\section{Embitterment, Social Exclusion, and the Intention to Vaccinate}

Our results support the view that a loss of resources, most likely attributed to the measures of the government, seems to result in feeling disconnectedness from the society and embitterment. The results suggest that with a loss of resources, such as social capital, freedom of mobility, or financial security, the perception of being marginalized as well as bitter thoughts and feelings step up. Additionally, this process was facilitated by the communication style of the government. That is, individuals' dissatisfaction with governmental communication may stem from a lack of clarity and understanding on how and which resources are being retracted from them. This also goes along with bitterness in the notion that resource losses are perceived not only as more significant (principle one; [5]) but also may perceive the loss due to the measures as an unjust transgression [7].

However, it seems that the perceived social exclusion represents an important connection with the bitterness of an individual. Our results suggest that it is less a matter of the cumulative impairment caused by the pandemic than to feel marginalized by the society that goes along with bitter ideas. The feeling of being socially excluded due to the pandemic is accompanied by a profound feeling of disappointment, an external locus of control, contempt, and a pessimistically stance on future events [9]. Moreover, we interpret the result also in light of created distrust. As trusting others is said to be one of the core social motives [43], individuals feeling socially excluded due to the pandemic may face shattered assumptions about their social world ([43], p. 12). These shattered assumptions contain "their ability to have confidence in the intentions of others" (p. 13) and that they are a valuable part of society. Hence, not only are these assumptions accompanied by feelings of embitterment but also may facilitate noncompliance to public health interventions [44].

On the other hand, although both processes are inter-related, they seem to go with different intentions. While perceived social exclusion goes hand-in-hand with a refusal of a potential vaccination, surprisingly embitterment was associated with an endorsement of vaccination. We interpret this finding that in the eyes of individuals with a bitter attitude, the vaccination represents a more suitable solution to their current problems than for people who feel socially excluded. That is, for embittered individuals, a vaccination may be seen as a potential resource to be invested in order to preserve resources and avoid more losses, such as the potential loss of a job or leisure activity in case of a vaccination refusal [5]. This also goes in line with the findings of Muschalla et al. [7], where embitterment was more connected with worries about the pandemic (e.g., job loss) than worries about the virus itself. In addition, since individuals showing a high degree of embitterment feel that their deeds are not recognized [14], they may feel that the vaccination is somewhat of an indemnity, which is why they might particularly feel privileged to receive a vaccination. For a follow-up study, it would thus be interesting to investigate if during the COVID-19 pandemic the actual vaccination can indeed increase feelings of satisfaction, internal locus of control, and a more optimistic stance on future events, and as such decrease embitterment in those individuals.

\section{Embitterment, Distrust, and Conspiracy Beliefs}

According to the results of this survey, an environment processed through bitterness was associated with the receptiveness to engage in conspiracy beliefs. While embitterment came along with a meaningful advocacy of being vaccinated, individuals also appeared to be sensitive to alternative explanations (e.g., political motives [45]) for the injustices suffered and developed the tendency to think more about the content of conspiracy beliefs. Embitterment goes along with an inherent distrust in the environment $[11,14]$ processing the environment into confederates or enemies. Interestingly, in our study, the association between embitterment and conspiracy beliefs had only been significant in individuals who were unsatisfied with the communication of the government during the COVID-19 pandemic. As recommended by Kim and Kreps [31], communication should be transparent and clear. When however political leaders communicate poorly, information may be processed as untrustworthy, thus processing these leaders as enemies. With 
this position, collecting alternative explanations about the injustices endured, building new alliances with people also engaging in conspiracy beliefs, and show noncompliance with measures [19] may increase a sense of control and belonging. This ultimately can be experienced as a resource gain. As previously mentioned, gains of resources are of especially high value in times of resource loss (principle 3, [5]).

Taken together, results suggest that the more an individual feels negatively affected by the interventions due to the pandemic, the more this individual is willing to invest in a vaccine in order to regain resources. When however resource losses go in hand with feelings of being socially excluded, are perceived as eminently unjust, and government's communication is perceived as disappointing, individuals tend to seek alternative explanations, which may make them prone to conspiracy beliefs. This in turn massively declines the intent to vaccinate against COVID-19.

\section{Acute (State) Embitterment and Chronic (Trait) Embitterment}

As mentioned above, embitterment may turn into a trait, leading to an individual's function by aspects of bitterness. It is important to note that state-like accentuations are still possible [9]. Clearly, results from this study and from Muschalla et al. [7] show evidence that pandemic-related stress may be associated with embitterment. Still, it may be possible that individuals high in state-embitterment may engage differently in vaccination offers than chronic (trait) embittered individuals. Whereas trait-embittered individuals may perceive the current development as an affirmation of their pessimistic and misanthropic mindset, state-embittered individuals may still be hopeful for change. Thus, latter may engage in resources that potentially give them redemption (e.g., a vaccination).

\section{Limitations and Future Research}

Since this is a cross-sectional study, clear connections, but no causal statements, can be made about the phenomena recorded. Further, the sample size in the study is small, hence limiting the statistical backing of the results. Thus, the illustrated effects should be interpreted carefully, even though they turned out to be robust. Second, results stem from a convenience sample; therefore, generalizations to the general public are limited, especially since a self-selection bias cannot be ruled out. Third, although the Conspiracy Beliefs Scale showed a high internal consistency, it was not previously validated on an in- dependent sample. In terms of content, the scale also includes conspiracy beliefs that are either no longer current or current ones are not listed. Last, as we assessed general (trait) embitterment, data do not reveal whether the embitterment scores are to be interpreted as a reaction to the pandemic (state) or if these individuals already had higher levels of embitterment before the pandemic (trait). Thus, longitudinal studies should assess whether differences in embitterment levels are associated with differences in terms of vaccination intentions.

Many questions still remain open, such as which other factors contribute to conspiracy beliefs and why social exclusion but not embitterment is negatively related to the intent to vaccinate. Future research should therefore endeavor to obtain longitudinal section data so that causal statements can also be made. Subsequently, in view of the following epidemiological "waves," it could be observed which influences embitterment has on the willingness to adhere to the measures.

\section{Conclusions}

- Individuals particularly affected by the pandemic intend to take up a possible vaccination against COVID-19.

- Health care professionals who experience bitter patients should address the possible functions of conspiracy beliefs in terms of resource gains and should seek and develop alternative strategies in order to gain new resources within the current situation.

- Governments should avoid communicating opaque or vague, as unclear communication might increase the susceptibility for conspiracy beliefs, which decrease the intention to vaccinate. As such, access to relevant health information should be fostered and the communication behavior of the government should be evaluated on a regular basis.

- Embitterment seems to be linked with conspiracy beliefs. This in turn, may have antisocial potential.

\section{Acknowledgments}

We like to thank M.Sc. Vica M. J. Tomberge and Prof. Dr. Jennifer Inauen for their support in the analysis and in the development of the manuscript. Further, we like to thank Dr. Adrian Lundberg, Dr. Marcia Rinner, M.Sc. Katrin Meier, and Catherine Plattner-Leo for their support in translating the questionnaires. 


\section{Statement of Ethics}

Approval for the study was given by the Ethics Commission of the faculty of human sciences, University of Bern (Nr. 2020-1000006). All the participants gave written informed consent.

\section{Conflict of Interest Statement}

The authors declare that they have no conflicts of interest.

\section{Funding Sources}

The raffle was financed with the help of departmental funds from the department of health psychology and behavioral medicine.

\section{Author Contributions}

D.K. conceptualized the study, built the questionnaire, organized data collection, formally analyzed data, and drafted the manuscript. M.I.P. and H.Z. contributed to the interpretation of the data and critically revised the manuscript for intellectual content. All authors read and approved the final manuscript.

\section{Data Availability Statement}

Data from individual anonymized subjects are available to other researchers upon request. Our statistical code or a detailed description of the various effects is available on request from D.K. Any request including a brief proposal should be directed to D.K.

\section{References}

1 De Quervain DJF, Aerni A, Amini E, Bentz D, Coynel D, Gerhards C, et al. The Swiss Corona Stress Study. OSF Preprints [Preprint].

2 Dubé E, Gagnon D, MacDonald NE; SAGE Working Group on Vaccine Hesitancy. Strategies intended to address vaccine hesitancy: review of published reviews. Vaccine. 2015; 33(34):4191-203.

3 Schmid P, Rauber D, Betsch C, Lidolt G, Denker ML. Barriers of influenza vaccination intention and behavior: a systematic review of influenza vaccine hesitancy, 2005-2016. PLoS One. 2017;12(1):e0170550.

4 Hobfoll SE. Conservation of resources theory: its implication for stress, health, and resilience. In: Folkman S, editor. The Oxford handbook of stress, health, and coping. Oxford: Oxford University Press; 2012.

5 Buchwald P, Hobfoll SE. Die Theorie der Ressourcenerhaltung: Implikationen für den Zusammenhang von Stress und Kultur. In: Genkova P, Ringeisen T, Leong FTL, editors. Handbuch stress und Kultur. Wiesbaden: Springer Fachmedien; 2013. p. 127-38.

6 Linden M. Posttraumatic embitterment disorder. Psychother Psychosom. 2003;72(4): 195-202.

7 Muschalla B, Vollborn C, Sondhof A. Embitterment as a specific mental health reaction during the coronavirus pandemic. Psychopathology. 2021;54(5):232-41.

8 Linden M, Schippan B, Baumann K, Spielberg R. Die posttraumatische Verbitterungsstörung (PTED). Nervenarzt. 2004; 75(1):51-7.

9 Znoj H. Embitterment: a larger perspective on a forgotten emotion. In: Linden M, Maercker A, editors. Embitterment: societal, psychological, and clinical perspectives. Vienna: Springer; 2011. p. 5-16.

10 Lee JH, Kim S. Exposure to negative life events and post-traumatic embitterment symptoms in young adults in Korea: cumulative and differential effects. Psychopathology. 2019;52(1):18-25.

11 Linden M. Querulant delusion and post-traumatic embitterment disorder. Int Rev Psychiatry. 2020;32(5-6):396-402.

12 Alexander J. The psychology of bitterness. Int J Psychoanal. 1960;41:514-20.

13 Znoj H. BVI: Berner Verbitterungs-Inventarmanual. Bern: Huber Hogrefe; 2008.

14 Znoj H, Abegglen S, Buchkremer U, Linden $M$. The embittered mind. J Individ Differ. 2016;37(4):213-22.

15 You M, Ju Y. Modeling embitterment dynamics: the influence of negative life events and social support mediated by belief in a just world. J Affect Disord. 2020;274:269-75.

16 Linden M, Baumann K, Rotter M, Schippan $B$. The psychopathology of posttraumatic embitterment disorders. Psychopathology. 2007; 40(3):159-65

17 De Sousa A, D'souza R. Embitterment: the nature of the construct and critical issues in the light of COVID-19. Healthcare. 2020;8(3): 304.

18 He J, He L, Zhou W, Nie X, He M. Discrimination and social exclusion in the outbreak of COVID-19. Int J Environ Res Public Health. 2020;17(8):2933.

19 Nivette A, Ribeaud D, Murray A, Steinhoff A, Bechtiger L, Hepp U, et al. Non-compliance with COVID-19-related public health measures among young adults in Switzerland: insights from a longitudinal cohort study. Soc Sci Med. 2021;268:113370.

20 Seifert A, Cotten SR, Xie B. A double burden of exclusion? Digital and social exclusion of older adults in times of COVID-19. J Gerontol B Psychol Sci Soc Sci. 2021;76(3):e99-103.

21 Shanahan L, Steinhoff A, Bechtiger L, Murray AL, Nivette A, Hepp U, et al. Emotional distress in young adults during the $\mathrm{CO}$ -
VID-19 pandemic: evidence of risk and resilience from a longitudinal cohort study. Psychol Med. 2020:1-10. Epub ahead of print.

22 Earnshaw VA, Eaton LA, Kalichman SC, Brousseau NM, Hill EC, Fox AB. COVID-19 conspiracy beliefs, health behaviors, and policy support. Transl Behav Med. 2020;10(4): 850-6.

23 Freeman D, Waite F, Rosebrock L, Petit A, Causier C, East A, et al. Coronavirus conspiracy beliefs, mistrust, and compliance with government guidelines in England. Psychol Med. 2020:1-13. Epub ahead of print.

24 Romer D, Jamieson KH. Conspiracy theories as barriers to controlling the spread of COVID-19 in the US. Soc Sci Med. 2020;263: 113356.

25 Georgiou N, Delfabbro P, Balzan R. COVID19-related conspiracy beliefs and their relationship with perceived stress and pre-existing conspiracy beliefs. Pers Individ Dif. 2020; 166:110201.

26 Kuhn SAK, Lieb R, Freeman D, Andreou C, Zander-Schellenberg T. Coronavirus conspiracy beliefs in the German-speaking general population: endorsement rates and links to reasoning biases and paranoia. Psychol Med. 2021:1-15. Epub ahead of print.

27 Swami V, Furnham A, Smyth N, Weis L, Lay A, Clow A. Putting the stress on conspiracy theories: examining associations between psychological stress, anxiety, and belief in conspiracy theories. Pers Individ Differ. 2016; 99:72-6.

28 Wang J, Jing R, Lai X, Zhang H, Lyu Y, Knoll $\mathrm{MD}$, et al. Acceptance of COVID-19 vaccination during the COVID-19 pandemic in China. Vaccines. 2020;8(3):482.

29 Kreps GL. The role of strategic communication to respond effectively to pandemics. Multicult Discourses. 2021;16(1):12-9. 
30 Briscoe C, Aboud F. Behaviour change communication targeting four health behaviours in developing countries: a review of change techniques. Soc Sci Med. 2012;75(4):612-21.

31 Kim DKD, Kreps GL. An analysis of government communication in the United States during the COVID-19 pandemic: recommendations for effective government health risk communication. World Med Health Policy. 2020;12(4):398-412.

32 Wilson KG, Sandoz EK, Kitchens J, Roberts $M$. The valued living questionnaire: defining and measuring valued action within a behavioral framework. Psychol Rec. 2010;60(2): 249-72.

33 Reilly ED, Ritzert TR, Scoglio AAJ, Mote J, Fukuda SD, Ahern ME, et al. A systematic review of values measures in acceptance and commitment therapy research. J Context Behav Sci. 2019;12:290-304.

34 Bude H, Lantermann E-D. Soziale exklusion und exklusionsempfinden. Kolner Z Soz Sozpsychol. 2006;58(2):233-52.
35 Kristensen K, König HH, Hajek A. The association of multimorbidity, loneliness, social exclusion and network size: findings from the population-based German Ageing Survey. BMC Public Health. 2019;19(1):1383.

36 Goreis A, Voracek M. A systematic review and meta-analysis of psychological research on conspiracy beliefs: field characteristics, measurement instruments, and associations with personality traits. Front Psychol. 2019; 10:205.

37 Blanca MJ, Alarcón R, Arnau J, Bono R, Bendayan R. Non-normal data: is ANOVA still a valid option? Psicothema. 2017;29(4):552-7.

38 Tofighi D, Kelley K. Indirect effects in sequential mediation models: evaluating methods for hypothesis testing and confidence interval formation. Multivariate Behav Res. 2020;55(2): 188-210

39 Vartanian LR, Froreich FV, Smyth JM. A serial mediation model testing early adversity, self-concept clarity, and thin-ideal internalization as predictors of body dissatisfaction. Body Image. 2016;19:98-103.
40 Yu Y, Yang X, Wang S, Wang H, Chang R, Tsamlag $\mathrm{L}$, et al. Serial multiple mediation of the association between internet gaming disorder and suicidal ideation by insomnia and depression in adolescents in Shanghai, China. BMC Psychiatry. 2020;20(1):460.

41 Taylor AB, MacKinnon DP, Tein J-Y. Tests of the three-path mediated effect. Organ Res Methods. 2008;11(2):241-69.

42 Preacher KJ, Rucker DD, Hayes AF. Addressing moderated mediation hypotheses: theory, methods, and prescriptions. Multivariate Behav Res. 2007;42(1):185-227.

43 North MS, Fiske ST. Driven to exclude: how core social motives explain social exclusion. In: DeWall CN, editor. The Oxford handbook of social exclusion. Oxford: Oxford University Press; 2013. p. 31-42.

44 Arriola LR, Grossman AN. Ethnic marginalization and (non)compliance in public health emergencies. J Polit. 2020;83(3):807-20.

45 Poutvaara P, Steinhardt MF. Bitterness in life and attitudes towards immigration. Eur J Political Econ. 2018;55:471-90. 